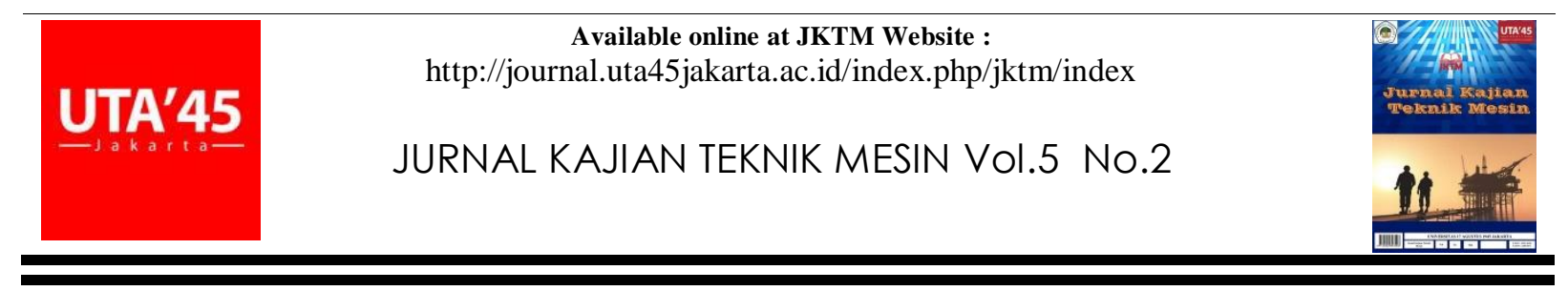

JurnalArtikel

\title{
Analisa Pengaruh Variasi Arus Listrik Pengelasan Terhadap Kekuatan Sambungan Pengelasan MIG Pada Material ST 37
}

\author{
Wenny Marthiana $^{1 *}$, Yovial Mahyoedin ${ }^{1}$, Duskiardi $^{1}$, Afri Rahim ${ }^{2}$ \\ ${ }^{1}$ Program studi Teknik Mesin, Fakultas Teknologi Industri, Universitas Bung Hatta, Padang \\ ${ }^{2}$ Jurusan Teknik Mesin, Politeknik Negeri Padang \\ *wenny_ma@yahoo.com
}

Artkel Info - : Received : 2 Aug 2020; Revised : 28 Aug 2020; Accepted: 31 Aug 2020

\begin{abstract}
Abstrak
Pada proses produksi, pengaturan parameter poses memegang peranan penting terhadap tercapainya mutu produk yang dihasilkan. Pada proses pengelasan, salah satu parameter proses pengelasan yang harus diperhatikan adalah besar arus pengelasan. Kajian ini dilakukan untuk mengetahui besar kuat arus yang sesuai pada proses pengelasan material ST 37 menggunakan proses pengelasan MIG (Metal Inert Gas). Pengujian dilakukan dengan memvariasikan besar kuat arus pengelasan yaitu pada 90A, 100A, 110A serta 120A. Pengujian tarik dilakukan terhadap hasil pengelasan tersebut. Hasil pengujian tarik menunjukkan, pengelasan menggunakan kuat arus sebesar $110 \mathrm{~A}$ memberikan nilai yang maksimum pada beberapa besaran pengujian. Untuk nilai tegangan tarik, $\sigma$ memiliki nilai $16.9 \mathrm{~kg} / \mathrm{mm}^{2}$, modulus elastisitas, E, $3.14 \mathrm{~kg} / \mathrm{mm}^{2}$ serta Regangan $\varepsilon, 5.42 \%$.
\end{abstract}

Kata kunci: pengelasan, Metal Inert Gas, Tegangan Tarik, modulus elastisitas

\section{Abstract}

The appropriate production parameter process plays an important role in fulfill the quality of the products such as mechanical properties like tensile strength and percentage of elongation of MIG welded joints. Likewise, in the welding process, one of the welding process parameters that is welding current must be considered, since the welding current is most influential parameters affecting weld penetration, deposition rate, weld bead geometry and quality of weld metal. Variation of welding current on MIG (Metal Inert Gas) welding process on ST 37 specimen was to examine the effects on like tensile strength and percentage of elongation and elasticity modulus. From the experiment, it is found that when welding current increased up to 110 Ampere the tensile strength tends to incline then slightly decline when welding current increased, modulus elasticity value and percentage of elongation value as well. The maximum value of tensile strength $16.9 \mathrm{~kg} / \mathrm{mm}^{2}$ percentage of elongation value $5.42 \%$. and modulus of elasticity $3.14 \mathrm{~kg} / \mathrm{mm}^{2}$ were gained at 110 ampere welding current

Keywords: welding process, Metal Inert Gas, Tensile strength, elasticity modulus ,percentage of elongation

\section{PENDAHULUAN}

Proses penyambungan logam menggunakan metoda welding sangat banyak dimanfaatkan dalam industri. Salah satu jenis pengelasan adalah MIG (Metal Innert Gas), dimana proses penyambungan dua material logam atau lebih menjadi satu melalui proses pencairan setempat dengan menggunakan elektroda gulungan (filler) berupa kawat yang sama dengan logam dasar yang disambung (base metal) dan menggunakan gas pelindung (inert gas).

Untuk memperoleh kualitas produk hasil pengelas, termasuk pengelasan MIG, sangat dipengaruhi oleh parameter proses pengelasan tersebut. Menurut Achmadi [1] Parameter pengelasan merupakan variabel 
yang mempengaruhi dari hasil pengelasan, baik dari hasil pengujian mekanik maupun uji visual. Jika pemilihan parameter las kurang tepat maka dapat mengakibatkan terjadinya cacat las dan sifat mekanik hasil pengelasan kurang dari syarat keberterimaan yang ditentukan oleh standar atau code. Prosedur pengelasan adalah pemilihan parameter las seperti tegangan busur las, besar arus las, penetrasi, kecepatan pengelasan dan beberapa kondisi standar pengelasan seperti bentuk kampuh las, tebal pelat, jenis elektroda, diameter inti elektroda, dimana parameter-parameter tersebut mempengaruhi sifat mekanik logam las. [2]. Pouranvari (dalam haikal triyono) [3] menyatakan adanya pengaruh kuat arus listrik pada las titik untuk baja dengan ketebalan berbeda terhadap kekuatan tarik

\subsection{Pengelasan MIG}

Proses pengelasan MIG (metal Inert Gas), yaitu panas dari proses pengelasan ini dihasilkan oleh busur las yang terbentuk diantara elektroda kawat (wire elektrode) dengan benda kerja. Selama proses las MIG (metal inert gas), elektroda meleleh kemudian menjadi deposit logam las dan membentuk butiran las (weld beads). Gas pelindung digunakan untuk mencegah terjadinya oksidasi dan melindungi hasil las selama masa pembekuan (solidification) [4]

Dalam las MIG ini gas yang digunakan adalah gas argon, helium atau campuran keduanya. Untuk memantapkan busur kadang-kadang ditambahkan gas $\mathrm{O}_{2}$ antara $2 \%$ sampai $5 \%$ atau $\mathrm{CO}_{2}$ antara $5 \%$ sampai $20 \%$. Las MIG biasanya dilaksanakan secara otomatik atau semi otomatik dengan arus searah (DC) polaritas balik dan menggunakan kawat elektroda berdiameter 1,2 sampai dengan 2,4 $\mathrm{mm}$ [2]. Pada pengelasan MIG terdapat 7 parameter proses pengelasan yang meliputi 1 . Kuat arus 2. Tegangan busur 3. Kecepatan Pengelasan 4. Ukuran elektroda 5. Laju aliran gas 6. Komposisi Shielding Gas 7.
Posisi pengelasan yang harus diperhatikan [5]

\subsection{Pengujian Tarik}

Pengujian tarik merupakan pengujian mekanis untuk mengetahui respon atau perilaku mekanis atau fenomena atomik serta mikroskopis material terhadap pembebanan atau deformasi luar, dimana fenomena tersebut tidak tergantung pada bentuk maupun ukuran dari benda uji.

Prinsip pengujian tarik adalah pemberian beban tarik pada specimen dengan ukuran dan bentuk tertentu ditarik dengan beban kontinu hingga bahan uji putus sambil diukur pertambahan panjangnya. Perubahan panjang yang telihat dalam kurva dikenal sebagai regangan. Regangan didefinisikan sebagi perubahan panjang yang terjadi akibat perubahan statik $(\Delta \mathrm{L})$ terhadap panjang batang mulamula $(L o)$. Selain regangan, pada proses penarikan juga terjadi tegangan teknik $(\sigma)$, adapun tegangan didefinisikan sebagai nilai pembebanan yang dialami $(\mathrm{F})$ pada luas penampang awal benda uji $(A o)$. [6]

Besarnya kekuatan tarik yang dialami benda uji dapat diformulasikan pada pers 1

$$
\sigma=\frac{F}{A_{0}}
$$

Nilai regangan yang terjadi dari pengujian dapat diperoleh melalui persamaan 2, yaitu

$$
\text { regangan, } \varepsilon=\frac{\Delta L}{L_{0}} X 100 \%
$$

Nilai Modulus Elastisitas, E diberikan:

$$
\mathrm{E}=\frac{\sigma}{\varepsilon}
$$

Dimana:

$$
\begin{aligned}
& \sigma: \text { Kekuatan Tarik }\left(\mathrm{Kg} / \mathrm{mm}^{2}\right) \\
& \mathrm{F}: \text { Beban maksimum yang mampu } \\
& \quad \text { ditahan spesimen }(\mathrm{Kg}) \\
& \mathrm{A}_{\mathrm{o}}: \text { Luas penampang awal specimen } \\
& \left(\mathrm{mm}^{2}\right) \\
& \varepsilon: \text { Regangan }(\%) \\
& \Delta \mathrm{L}: \text { Perpanjangan }(\mathrm{mm}) \\
& \text { Lo : Panjang awal }(\mathrm{mm}) \\
& \mathrm{E}: \text { Modulus elastisitas }\left(\mathrm{kg} / \mathrm{mm}^{2}\right)
\end{aligned}
$$




\section{METODA PENELITIAN}

Pelaksanaan penelitian digambarkan dalam diagram alir pada gambar 1

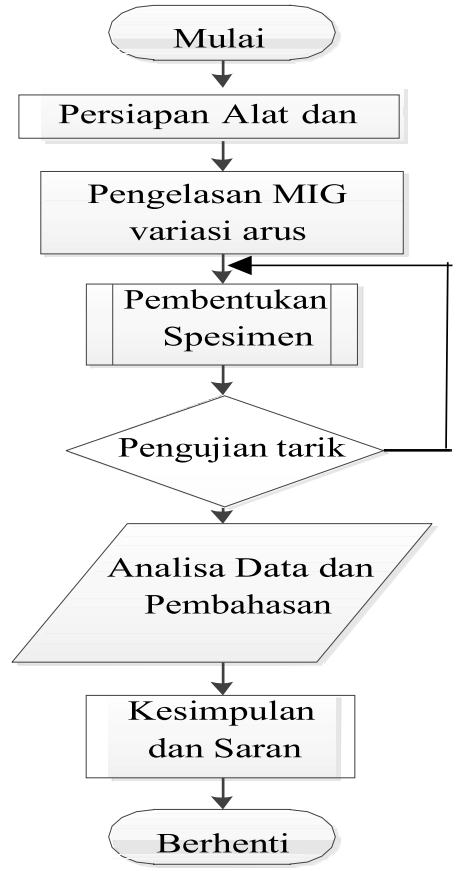

Gambar 1. Diagram Alir Penelitian

\subsection{Spesimen Pengujian}

Gambar 2 menunjukkan spesimen pengujian tarik yang digunakan, mengacu pada standard ASTM E8, dengan dimensi seperti ditunjukkan tabel 1 .

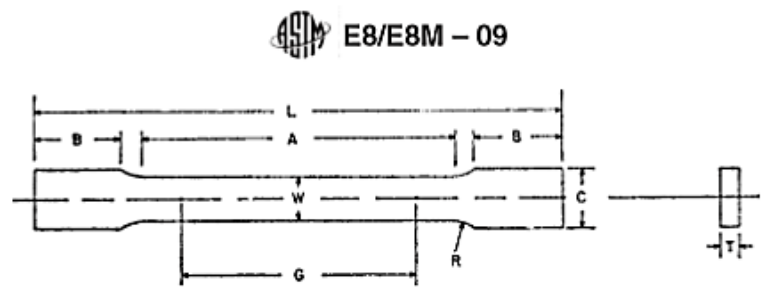

Gambar 2. Spesimen pengujian Tarik

Tabel 1. Dimensi Spesimen Tarik ASTM E8

\begin{tabular}{ccccccccc}
\hline Spesi & \multicolumn{1}{c}{ Dimensi (mm) } \\
men & G & W & C & R & L & A & B & T \\
\hline & 5 & 12 & 2 & 12 & 20 & 5 & 5 & 3 \\
& 0 & .5 & 0 & .5 & 0 & 7 & 0 & \\
\hline
\end{tabular}

\subsection{Parameter pengujian}

Dalam penelitian ini beberapa parameter pengujian ditentukan lebih dahulu, yaitu:

1.Perencanaan tegangan. Tegangan yang diambil dalam penelitian ini adalah $24 \mathrm{~V}$ dan dijaga konstan

2. Kecepatan $20 \mathrm{inch} / \mathrm{menit}$

3. Variasi arus, 90,100, 110 dan 120 ampere

4. Diameter elektroda, $1.2 \mathrm{~mm}$

\section{HASIL DAN PEMBAHASAN}

Spesimen hasil pengelasan setelah mengalami uji Tarik ditunjukkan pada gambar 3 hingga 7

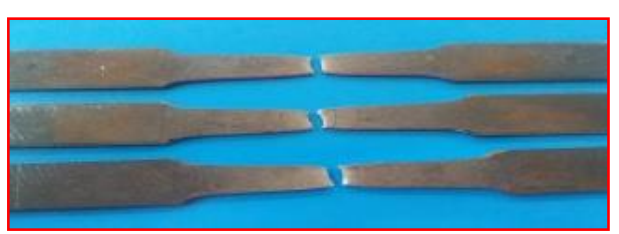

Gambar 3. Spesimen Kontrol

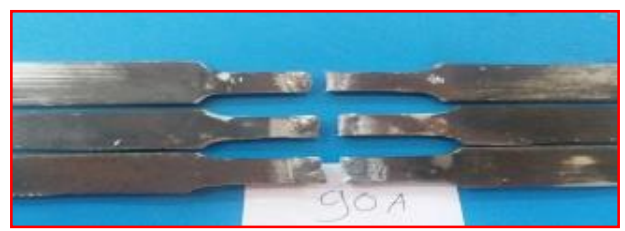

Gambar 4. Spesimen dengan I = 90 A

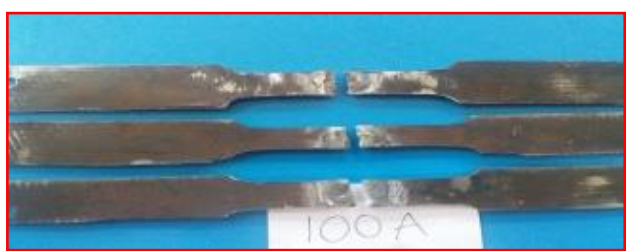

Gambar 5. Spesimen dengan $\mathrm{I}=100 \mathrm{~A}$

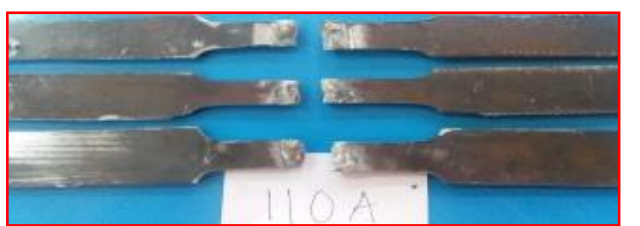

Gambar 6. Spesimen dengan $\mathrm{I}=110 \mathrm{~A}$

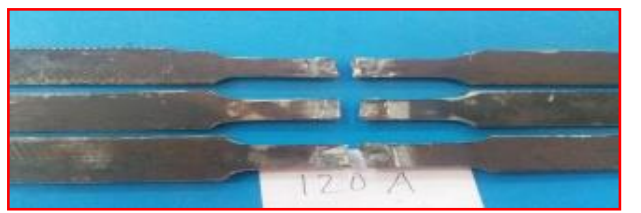

Gambar 7. Spesimen dengan $\mathrm{I}=120 \mathrm{~A}$ 


\subsection{Hasil Pengujian}

Hasil pengujian memberikan nilai Kekuatan tarik, regangan serta modulus elastisitas seperti ditunjukkan pada gambar 8 hingga gambar 10.

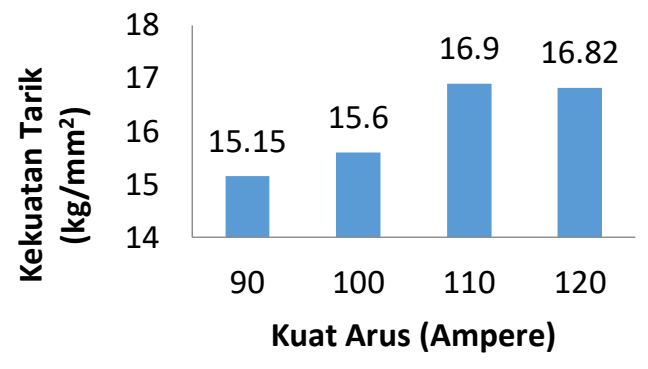

Gambar 8. Pengaruh Kuat Arus terhadap kekuatan tarik

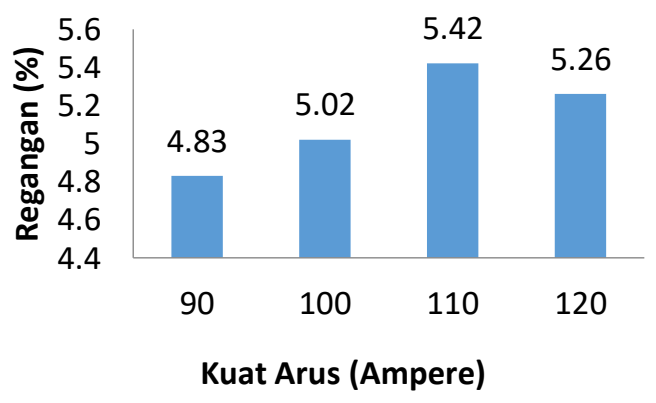

Gambar 9. Pengaruh Kuat Arus terhadap Regangan

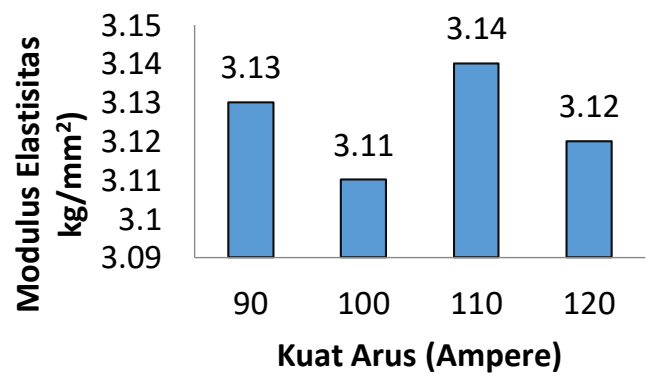

Gambar 10. Pengaruh Kuat Arus Modulus Elastisitas

Nilai Pengujian Spesimen Kontrol yang diperoleh adalah:

1. Kekuatan tarik rata-rata $38.62 \mathrm{~kg} / \mathrm{mm}^{2}$.

2. Regangan rata-rata $5.13 \%$

\subsection{Pembahasan}

Dari hasil pengujian terlihat bahwa variasi besar arus pengelasan berpengaruh terhadap nilai kekuatan Tarik dan regangan.

Menurut Raharjo [7], kuat arus pengelasan sangat berpengaruh pada kekuatan tarik dan kekuatan impact suatu material. Pada variasi kuat arus yang sangat rendah, material menjadi rapuh. Menurutnya, kuat arus yang sangat rendah mengakibatkan ukuran butir mengecil sehingga jarak antar butir semakin jauh, ikatan melemah, dan rapuh. Kondisi ini menyebabkan material amat mudah patah, sehingga energi yang dibutuhkan untuk menarik dan mematahkannya sangat kecil pula. Selanjutnya dengan bertambahnya kuat arus pengelasan, maka ukuran butir makin membesar sehingga jaraknya semakin dekat dan ikatannya menguat serta kekuatan tarik dan ketangguhannya meningkat. Dengan demikian kekuatan tarik dan kekuatan impactnya meningkat. Kemudian apabila temperatur makin meningkat, hingga material mencapai keuletan sampai pada temperatur maksimalnya, energi yang dibutuhkan untuk menarik dan mematahkannya akan bertambah pula sampai nilai maksimum. Selanjutnya jika lewat dari titik ini, maka energi akan menurun karena adanya deformasi.

Hasil pengujian menunjukkan bahwa penambahan kuat arus hingga $110 \mathrm{~A}$ menghasilkan peningkatan pada kekuatan tarik dan regangan. Hasil ini senada dengan yang ditemukan oleh [7], yaitu semakin besar kuat arus maka ukuran butir makin membesar, jarak butir semakin dekat dan ikatan semakin kuat, yang pada gilirannya meningkatkan kekuatan dan ketangguhan material.

Hasil pengujian juga menunjukkan bahwa penambahan kuat arus hingga menjadi 120A memberikan fenomena terjadinya penurunan pada besaran kekuatan tarik dan regangan. Mengacu pada penelitian [7], hasil tersebut memperlihatkan telah terjadinya deformasi pada material, sehingga kekuatan dan ketangguhan material menurun.

Pada sisi lain, nilai Modulus elastisitas 
pada keseluruhan pengujian menunjukkan nilai yang perbedaan sangat kecil. Modulus elastisitas diukur terhadap tegangan luluh material. Pada material hasil pengelasan, tegangan luluh bahan dapat diperkirakan mendekati tegangan maksimum yang terjadi. Wiryosumarto (8) menyatakan bahwa kekerasan dan kegetasan pada material pengelasan tidak mampu menutupi pengaruh tegangan sisa saat pendinginan setelah pengelasan. Tegangan sisa yang terjadi menimbulkan keretakan pada daerah pengelasan. Akibatnya, daerah pengelasan memiliki kekuatan Tarik yang menurun akibat cacat retak yang terbentuk selama pendinginan dan tidak mampu mengalami pertambahan panjang saat pengujian Tarik dilakukan. Ketidakmampuan tersebut ditunjukkan oleh nilai modulus elastisitas yang hampir tidak jauh berbeda pada variasi kuat arus. Dengan kata lain, pengujian menunjukkan bahwa material pengelasan adalah getas berapapun nilai kuat arus yang diberikan.

\section{KESIMPULAN DAN SARAN}

\subsection{Kesimpulan}

Dari penelitian dapat diambil kesimpulan sebagai berikut:

1. Variasi kuat arus listrik menunjukkan bahwa sambungan las MIG memberikan pengaruh terhadap kekuatan sambungan las.

2. Kekuatan sambungan las tertinggi diperoleh pada pengelasan yang menggunakan kuat arus sebesar 110A, dengan nilai $16,9 \mathrm{~kg} / \mathrm{mm}^{2}$

3. Regangan terbesar pada hasil pengelasan menggunakan kuat arus sebesar 110 A dengan nilai $5.42 \%$

4. Nilai modulus elastisitas hasil pengelasan sebesar $3,14 \mathrm{~kg} / \mathrm{mm}^{2}$ pada hasil pengelasan $110 \mathrm{~A}$

\subsection{Saran}

Berdasarkan hasil penelitian yang telah dilaksanakan, maka disarankan agar untuk mengetahui pengaruh kuat arus sebaiknya dilakukan pengujian dengan jenis kampuh las yang berbeda.

\section{DAFTAR PUSTAKA}

[1] Achmadi. Pengelaasan .net., juni 2020

[2] Muku and Krishna Made I Dewa, Kekuatan Sambungan Las Aluminium Seri 1100 dengan Variasi Kuat Arus Listrik Pada Proses Las Metal Inert Gas ( MIG ) Cakram, vol. 3, no. 1, pp. 11-17, 2009.

[3] Pouranvari, M., 2011, "Effect of Welding Current on the Mechanical Response of Resistance Spot Welds of Unequal Thickhness Steel Sheets in Tensile-Shear Loading Condition: International Journal of Multidisciplinary Science and Engineering," Vol. 2, No. 6.

[4] B. Mishra, R. R. Panda, and D. K. Mohanta, Metal Inert Gas ( Mig ) Welding Parameters Optimization," no. June, pp. 637-639, 2014

[5] C. Labesh kumar, T. Van aja, KGK Murti. 2017. Optimization of Mig Welding Process Parameters for Improving Welding Strength of Steel. International Journal of Engineering Trends and Technology (IJETT) - Volume 50:1

[6] W. D. Callister. 2014. Materials Science And Engineering, New Jersey. Wiley, Sixth Edition

[7] Raharjo, Samsudi \& Rubijanto J.P. 2012. Variasi Arus Listrik Terhadap Sifat Mekanis Sambungan Las Shielding Metal Arc Welding (SMAW). Jurnal FT UMS, 14129612

[8] Syaripuddin, S., Susetyo, F. B., Aribowo, A. H., \& Nofendri, Y. (2019). Kekuatan Tarik Multilapis Deposit Las Beberapa Produk Komersial Elektroda AWS A. 51 E6013. MECHANICAL, 10(1), 1518. 